\section{RESENHA CRÍTICA: SUJEITOS DO CAMPO EM MOVIMENTO: DIREITOS, RESISTÊNCIAS E PRÁTICAS FORMATIVAS}

Áurea Silva Moura ${ }^{1}$

Domingos Rodrigues da Trindade, possui graduação em licenciatura plena em Pedagogia, mestrado e doutorado em Educação, professor adjunto do Departamento de Educação, Campus XII/UNEB, professor do Programa de Pós-graduação em Educação (Mestrado). Leila Lôbo de Carvalho, possui graduação em Pedagogia, mestranda em Educação.

Professora da rede pública de Guanambi. Maria Osanette de Medeiros, é licenciada em Pedagogia, Mestra em Educação na área de currículo e metodologia do ensino, doutora em Educação: área: Educação e Ecologia Humana, atua principalmente nas áreas de orientação educacional, educação do campo e educação comunitária. Priscila Teixeira da Silva, graduada em Pedagogia, especialista em Alfabetização e Letramento, mestra em Educação do Campo doutoranda em Educação e Contemporaneidade, atualmente é professora substituta da Universidade do Estado da Bahia, Campus XII.

O autor do primeiro capítulo do livro mostra uma Pesquisa-Ação-Participante (PAP), na qual aconteceu em uma comunidade quilombola de Lagoa das Piranhas, município de Bom Jesus da Lapa-Ba. O texto traz reflexões sobre a PAP, para que não aconteça os distanciamentos entre a escola e a comunidade, muitos estudantes só vão ao campo coletar dados, sem se envolver em assumir um caráter político, participativo e emancipatório no local. O PAP dialoga com o projeto de libertação da classe oprimida, possibilitando um novo sentido de pesquisa, é analise do pesquisador aos sujeitos motivando-os á reinterpretação da realidade, com vistas a sua transformação.
TRINDADE, R. D. et al. Sujeitos do Campo em Movimento: direitos, resistências e práticas formativas, Curitiba: CRV, 2018. p.1-108.

O livro "Sujeitos do Campo em Movimento: direitos, resistências e práticas formativas" é constituído por dez capítulos, cada capítulo é de responsabilidade de seus respectivos autores, ao total a obra foi produzida por vinte e nove autores. As abordagens traduzem-se em resistência, empoderamento e do compromisso político dosldas autoreslas que lutam em defesa dos sujeitos do campo.

Submetido em: 04 de abr. 2019

Aceito em: 16 de mai. 2019

${ }^{1}$ Departamento de Educação - Campus XII, Universidade do Estado da Bahia, Guanambi, Bahia - Brasil.

E-mail para correspondência: aureamoura@hotmail.com.br 
Os autores do segundo capítulo, desenvolveu uma experiência de iniciação cientifica, nos anos de 2015 a 2017, vinculada a Universidade do Estado da Bahia Departamento de Educação Campus XII. Essa experiência mostra o descaso que o Estado se tem com as escolas do campo, muitas estão sendo fechadas sem o consentimento da comunidade, simplesmente fecham sem diálogo o qual vai contra a CNE\CEB 2002. Os mesmos realizaram uma entrevista e observaram que existem alunos que não conhecem a escola da própria comunidade.

Oslas autores (as) do terceiro capítulo discutem como a ciranda da Licenciatura em Educação do Campo na Universidade de Brasília LEDOCIUnB é importante na vida das mães e de seus respectivos filhos. Ela é uma expressão de luta e possibilidades concreta de acesso e permanecia das mulheres camponesas, no ensino superior e de vivencia por parte das crianças, pois ocupar uma vaga na universidade não é suficiente é necessário garantir que aconteça a permanência.

No quarto capítulo, as autoras mostram o projeto: Vozes do Rancho: um salto para as margaridas, aprovado pela chamada Interna de Extensão $n^{\circ}$ 02\2016 Projeto Margaridas do IF Baiano, em homenagem a Margarida Maria Alves, precursora feminista na Paraíba na defesa dos direitos dos trabalhadores do campo, a qual foi assassinada em 1983. O crime foi considerado político, comoveu e se teve uma grande repercussão.

O local que foi escolhido para a realização do projeto foi o Distrito de "Rancho das Mães", situado na zona rural do município de Palmas de Monte Alto - BA, a maioria da população é feminina, negra e apresenta altos índices de mães Solteiras de diversas faixas etárias, segundo fontes do próprio grupo, deram origem ao nome do povoado e justifica a escolha como campo de atuação. São 50 colaboradoras do projeto, equipe exclusivamente feminina.

No quinto capítulo, as autoras apresentam pesquisa de trabalho de conclusão de curso de Pedagogia da Universidade do Estado da Bahia Campus XII, o texto aponta que as escolas nas áreas rurais de Guanambi$\mathrm{Ba}$ foram extinguidas, restando apenas escolas nucleadas nos distritos de $\mathrm{Mu}-$ tãs, Morrinhos e Ceraíma. Que indica que desconsiderou a Resolução CNElCEB n 112002 que pede para ser evitado o fechamentolnucleação das escolas do campo. Em 2008 as Diretrizes Complementares, afirma que a Educação das séries inicias do fundamental para os povos do campo só deverão ser ofertadas em escolas no campo.

As autoras no capítulo seis abordam uma pesquisa feita com oslas jovens do campo participantes do Programa Jovem Saber vinculado ao Sindicato dos Trabalhadores Rurais Agricultores e Agricultoras Familiares da cidade de UrandilBA, que utilizou como instrumento metodológico o grupo focal. Nesta cidade $63,8 \%$ dosldas jovens de 15 a 29 anos residem no meio rural.

De acordo com as falas dos meninos no grupo focal observa-se que a minoria realiza atividades para ajudar, os demais só fazem quando a mãe ou a irmã não está em casa, as participantes reclamam que no futebol os homens tem direito a meia hora de jogo e as mulheres apenas 15 minutos, e ainda acontece a dependência do marido para as acompanharem.

Com o capítulo sete, ola autorla discute como a Pedagogia da Alternância (PA) tem contribuído para a permanência do jovem da Escola
Família Agrícola (EFA) de Riacho de Santana no meio rural, por meio da PA, os alunos passam uma parte do tempo com a família e a outra parte do tempo na escola, em ambos o aprendizado é constante.

Após os estudantes se tornarem alternantes da EFA melhorou a forma de se expressarem na comunidade, a participação em associações comunitárias; e o desenvolvimento econômico, social e ambiental do local. Mesmo os ex-alternantes que saem do campo para trabalhar em outras áreas investem na propriedade de modo que sua família trabalhe e tenha um melhor rendimento econômico.

Por falta de recursos o PA não é trabalhado como deveria ser trabalhado, pois sem os recursos financeiros os monitores não visitam a casa dos alunos. A visita é muito interessante, pois pode proporcionar Estudos adaptados ao meio de vida dos estudantes.

O capítulo oito, refere-se a uma pesquisa realizada na Escola $\mathrm{Mu}$ nicipal Celeste Laranjeira Malheiro na cidade de Monte Alto-BA, os participantes da pesquisa foram jovens e adultos do segmento I, o perfil dos estudantes são lavradores e diaristas, alunos da cidade e do meio rural no qual utilizam o transporte escolar para se chegar à escola, a maioria se declaram pardosinegros. $\mathrm{O}$ fato de terem abandonado a escola quando mais novos para trabalhar levam a eles não quererem desperdiçar, pois percebem o quanto a educação é importante no contexto atual. Na EJA também acontece à evasão escolar um dos motivos é que as mães não têm com quem deixar seus filhos nesse sentido é necessário implantar políticas públicas neste caso a Brinquedoteca.

A organização do trabalho pedagógico na EJA entende que ocorre a demanda de necessidades diferencia- 
das, pois essa forma de ensino contempla sujeitos heterogêneos.

Deve-se levar em conta também um projeto social fundamentado em teorias que se preocupem com uma escola democrática de qualidade, bem como a formação de sujeitos mais humanizados, críticos e conscientes da sua identidade e cidadania.

Com o penúltimo capítulo as autoras procuram criticar o descaso que acontece com os alunos do campo, principalmente com os de necessidades especiais que ali vivem, no qual acontece propositalmente, pois para a classe dominante é interessante se a classe dominada lidar com o plantio, o cuidado com os animais e o serviço doméstico.

No Brasil existem leis que garantem a inclusão social até mesmo nas escolas, mas infelizmente elas só estão no papel, não são aplicadas como deveria. Os alunos com deficiência têm o direito de frequentar escolas perto ás suas casas, e não devem ir só para passar o tempo. Nas escolas o professor deve ter algum curso para se trabalhar com esses estudantes, mas não é isso que acontece, podemos observar no questionário aplicado ás professoras da Rede Municipal de Ensino do município de Érico Cardoso- BA, das três professoras entrevistadas, elas só tinham a graduação.

Encerrando a obra, as autoras relatam uma pesquisa realizada sobre as práticas educativas da Articulação Semiárido Brasileiro (ASA) na microrregião de Guanambi - BA, a sua entidade recebe o nome de CASA. A proposta da ASA tem como princípios formativos a mobilização social, a gestão compartilhada; a descentralização da água, da terra e do poder; a valorização doslas agricultoreslas entre outros. A ação da ASA é disseminar tecnologias sociais como a cisterna de placas, tornando possível o armazenamento de água da chuva para utilizálas. Algo presente nas falas dos entrevistados é que essas cisternas diminui a migração dos sujeitos, acontece uma melhoria na qualidade da alimentação por meio das hortaliças e do consumo de água potável e acontece as reduções de doenças.

A obra é de fácil interpretação, pois sua linguagem não é rebuscada, e de um modo geral os autores apoiam-se e discutem em relação ao campo, trazem temas que se complementam e que são importantes e precisam ser discutidos, inclusive nesse cenário político atual como, por exemplo, o direito dos estudantes a escola do campo, o transporte escolar com monitores para o cuidado com as crianças principalmente as menores, professores capacitados para se trabalhar a inclusão, acesso á agua, evasão escolar, a desigualdade da mulher perante o homem, a necessidade de políticas públicas no campo, a falta de investimento na educação.

Depois de mais de vinte anos da promulgação da lei diretrizes e bases da educação (1996), acontece o congelamento de investimentos na educação, isso só mostra que estamos regredindo, se nas escolas da cidade não está fácil, imagine na escola do campo, as autoras do capítulo nove p.170 utilizam os conceitos de Saviani (2016) no qual ele faz denúncias a educação do campo, no qual se diz que o pobre não precisa aprender mais do que lidar com o plantio, o cuidado com os animais e os serviços domésticos, pois se a classe dominante investir em educação, eles perderiam a hegemonia.

Essa falta de investimento não favorece o estudante, pois se ele estudasse no campo não aconteceria tanta evasão escolar, pois muitos pais não têm condições de ir à escola dos seus filhos na cidade para acompanhar o rendimento escolar, até mesmo os alunos acabam achando a rotina cansativa de percorrer todo o longo percurso de sua casa até a escola.

Outro tema relevante que é discutido no livro é sobre a questão de gênero, que a mulher sempre esteve em desigualdade perante o homem, nos dias atuais criou-se a ilusão que a mulher está no mesmo patamar que o homem por trabalharem fora de casa, pura ilusão, pois a maioria das mulheres quando chega em casa ainda vão cuidar dos filhos, da casa, ou seja as atividades só aumentaram, as meninas desde cedo sempre trabalham nas atividades domésticas e quando o homem vai realizar, é colocado que eles estão apenas ajudando.

Sem dúvida, o livro causa nos leitores um impacto de reflexão, vem desconstruir e mostrar a verdade sobre determinados assuntos que já são considerados normais na sociedade e que na verdade não é, e sim apenas ações políticas que visam à alienação dos povos, a obra é de extrema relevância por se tratar de um dos assuntos mais importantes do contexto atual e tem por objetivo discutir temas referentes ao campo. É de grande auxilio a todos que trabalham com a educação e pesquisam sobre o tema, todos que engajam na luta para que os sujeitos do campo tenham uma vida mais digna e que tenha o que eles tem por direito. 